\title{
Explorando variáveis que afetam a adesão e a qualidade da tarefa de descrever competências utilizando guias instrucionais e oficinas de mapea- mento
}

\author{
César Augusto Barth \\ Camila Carvalho Ramos \\ Romariz da Silva Barros \\ Thiago Dias Costa
}

\section{RESUMO}

As competências são o eixo central do modelo de gestão por competências, assim, é essencial que elas sejam bem descritas. Uma boa maneira de realizar isso é solicitando aos próprios colaboradores que descrevam suas competências. Para auxiliar os trabalhadores na descrição, foi elaborado e testado um guia instrucional. 0 objetivo deste estudo foi: 1) identificar e manipular fatores impactantes na realização da tarefa de descrever competências utilizando um guia instrucional e 2) avaliar a qualidade das competências descritas. Participaram dos estudos 349 servidores componentes de 15 workshops em três órgãos públicos. Ao avaliar o impacto de determinados fatores sobre a adesão ao procedimento de descrever competências, os resultados demonstraram diferenças entre o relato dos servidores e os resultados de uma manipulação experimental. Um exemplo é o fator tempo, indicado pelos servidores como muito impactante sobre a tarefa, mas não confirmado experimentalmente. Os dados não indicaram diferenças significativas entre as competências descritas pelos servidores que apenas participaram dos workshops e servidores que participaram dos workshops e também utilizaram do guia instrucional. Pesquisas subsequentes devem explorar métodos para o aperfeiçoamento de guias e outros instrumentos para impulsionar a participação dos servidores e melhorar a qualidade de competências.

Palavras-chave: Mapeamento de competências; administração pública; guia instrucional

\section{ABSTRACT}

Exploring variables that affect the adherence and the quality of describing competence through instructional guides and mapping workshops

Competences are the central axis of the competence management model, so it is essential that they are well described. A good way to do this is by asking employees to describe their competences. To help workers in describing competences, an instructional guide has been developed and tested. The objective of this study was to: 1) identify and manipulate impacting factors in the accomplishment of the task of describing competencies using an instructional guide 2) evaluate the quality of the described competences. 349 members of 15 competency mapping workshops in three public agencies participated in the studies. When evaluating the impact of certain factors on adherence to the procedure of describing competences, the results showed differences between the report of the employees and the results of an experimental manipulation. An example is the time factor, indicated by the employees as very impacting on the task but not confirmed experimentally. The data did not show significant differences between the competences described by the employees that only attended the workshops and employees that participated in workshops and also used the instructional guide. Subsequent

\section{Sobre os Autores}

C.A.B.

orcid.org/0000-0003 -0495-

1252

Universidade Federal do Pará

(UFPA) - Belém, PA

cesar.barth@gmail.com

C.C.R.

orcid.org/0000-0002-9801-9361 Universidade Federal do Pará (UFPA) - Belém, PA

camilakrvalho@gmail.com

R.S.B.

orcid.org/0000-0002-1306-384X Universidade Federal do Pará (UFPA) - Belém, PA

romarizsb@gmail.com

T.D.C.

orcid.org/0000-0002-5443-5232 Universidade Federal do Pará (UFPA) - Belém, PA thiagodiascosta@gmail.com

\section{Direitos Autorais}

Este é um artigo aberto e pode ser reproduzido livremente, distribuído, transmitido ou modificado, por qualquer pessoa desde que usado sem fins comerciais. 0 trabalho é disponibilizado sob a licença Creative Commons CCBY-NC 


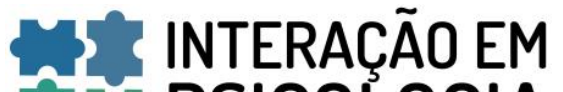 w Psicologia}

research should explore methods for improving guides and other tools to boost employees' engagement and improve the quality of competences.

Keywords: Competency mapping; public administration; instructional guide

A emergência de novos métodos, técnicas e tecnologias para a realização do trabalho nas organizações tem demandado uma maior capacitação de seus colaboradores. Para lidar com essa demanda, as organizações buscam treinar seus colaboradores ou contratar novos indivíduos com as competências requeridas. Em ambos os casos, é necessário identificar as competências essenciais para realização do trabalho na instituição e as já existentes nela. Ao identificar a lacuna existente entre as competências requeridas e as já disponíveis, a instituição poderá planejar ações para os indivíduos se capacitarem para a realização dos trabalhos (Bohlouli et al., 2017).

O desenvolvimento das competências necessárias para atingir os objetivos organizacionais se torna o foco da gestão de pessoas por competências, norteando todos os subsistemas da gestão de pessoas. Assim, é possível agregar, desenvolver, remanejar, manter e monitorar pessoas de acordo com suas competências (Carbone, Brandão, Leite, \& Vilhena, 2009). Portanto, a proposta fundamental desse modelo de gestão é eliminar ou reduzir substancialmente a lacuna entre as competências dos trabalhadores e as necessárias para a realização dos objetivos organizacionais (Brandão, 2012).

\section{MAPEAMENTO DE COMPETÊNCIAS}

O processo de gestão por competências compreende um conjunto de diversas etapas que podem variar conforme as características da organização. Tradicionalmente ela se inicia com a formulação da estratégia organizacional, definindo elementos tais como missão, visão de futuro e objetivos estratégicos da organização (Brandão \& Bahry, 2005; Carbone et al., 2009). Em seguida, são definidos indicadores de desempenho e metas, partindo dos objetivos estratégicos já estabelecidos (Brandão \& Bahry, 2005). Após a formulação da estratégia organizacional, a etapa de mapeamento de competências pode ser iniciada. 0 que está sendo aqui nomeado de "competência" é todo comportamento observável no ambiente de trabalho que tem relação direta com a consecução dos objetivos institucionais (Ramos, Costa, Borba, \& Barros, 2016). Assim, nessa etapa, são identificadas as competências necessárias para que a organização possa realizar seus objetivos, além do domínio de seus trabalhadores em relação a essas competências. Assim, é possível identificar a lacuna existente entre as competências necessárias e as competências já apresentadas pelos trabalhadores da instituição (Carbone et al., 2009).

Para a identificação da diversidade e grau de domínio das competências já apresentadas pelos trabalhadores da instituição, podem ser utilizadas diversas técnicas. Entre as técnicas relatadas na literatura encontramos a análise documental, entrevistas, grupos focais, aplicação de questionários e observações diretas (Carbone et al., 2009). A escolha das ferramentas deve ser realizada conforme as características da organização (Brandão, 2012).

Neste ponto, é importante destacar que administração pública possui alguns aspectos que a distinguem da administração de organizações privadas, inclusive na área de gestão de pessoas (Pinto \& Silva, 2015). Assim, antes da adoção das práticas efetivas do setor privado no contexto público, é necessário investigar sua adequação ao setor público, bem como criar novas metodologias voltadas para a administração pública (Pinto \& Silva, 2015; Siqueira \& Mendes, 2009). Considerando diversos aspectos do setor público, Ramos (2015), ao mapear competências nesse âmbito de administração, propõe um método similar ao de Brandão (2012). 0 método proposto contém etapas de análise documental e oficinas de mapeamento de competências para a identificação das competências de cada unidade. Posteriormente sugere uma etapa para avaliação das competências apresentadas pelos servidores, aferindo o grau de domínio de cada servidor em relação a cada uma das competências por meio de questionários e identificando as lacunas dessas competências (Ramos, 2015).

Durante a análise documental, diversos documentos institucionais são analisados para a identificação de possíveis competências necessárias para atingir os objetivos organizacionais. São analisados documentos que contêm descrições referentes às atribuições das unidades da instituição. Com base nessas descrições, são sugeridas competências que o trabalhador deveria ser capaz de fazer para realizar as atribuições sob sua responsabilidade (Brandão, 2012; Ramos, 2015).

Para participar das oficinas de mapeamento de competências, são convocados servidores com grande experiência e conhecimento sobre os processos das unidades organizacionais a serem mapeadas. As oficinas são realizadas presencialmente, por um grupo de facilitadores de mapeamento de competências. Cada oficina de mapeamento é composta por duas etapas. A primeira etapa consiste em uma apresentação oral, em que um facilitador experiente apresenta os objetivos da oficina de mapeamento e orienta os participantes acerca de como elaborar e descrever competências, seguindo uma série de cuidados metodológicos. Nessa metodologia de descrição de competências, os servidores descrevem os 
comportamentos necessários para realização do trabalho na sua unidade organizacional. Durante a segunda etapa, os participantes devem identificar, descrever e atribuir grau de importância para as competências. Para realizar essa atividade, os participantes poderão ter o auxílio de um grupo de facilitadores, por meio de orientações individualizadas, sanando dúvidas pontuais (Ramos, 2015).

Após a identificação das competências, são elaborados questionários contendo todas as competências relacionadas a cada uma das subunidades da organização. Nesta etapa, e através da aplicação desses questionários, os gestores avaliam seus subordinados e estes se auto avaliam, indicando o domínio (ou a grau de necessidade de capacitação) nas competências necessárias para realização de seu trabalho. Os resultados desta avaliação indicam a lacuna entre as competências necessárias para concretizar a estratégia da organização e as competências já existentes (Brandão, 2012).

\section{DESCRIÇÃO DAS COMPETÊNCIAS}

A descrição de uma competência exprime o comportamento esperado do indivíduo, indicando o que ele deve ser capaz de fazer durante trabalho (Carbone et al., 2009). Essa descrição repercutirá sobre todas as demais etapas da gestão por competências, assim, é essencial que as competências sejam bem descritas durante o mapeamento delas. Diversos autores na literatura sugerem uma série de orientações e cuidados metodológicos que devem ser tomados durante a formulação das competências, entre eles: 1) A descrição deve iniciar com um verbo que indique uma ação concreta, passível de observação (Brandão \& Bahry, 2005; Carbone et al., 2009; Ramos et al., 2016); 2) Evitar a descrição de competências múltiplas utilizando vários verbos ou complementos na mesma competência (Brandão \& Bahry, 2005; Ramos et al., 2016); 3) Evitar a descrição de competências que constituam intenções ou expectativas a serem alcançadas (Ramos et al., 2016); 4) Evitar fazer descrições de competências de forma vaga, com comportamentos descritos utilizando verbos que não exprimem ações que possam ser observadas diretamente (Brandão \& Bahry, 2005; Carbone et al., 2009; Ramos et al., 2016); 5) Evitar descrições contendo termos técnicos e estrangeirismos (Brandão \& Bahry, 2005; Carbone et al., 2009; Ramos et al., 2016) e 6) Evitar descrições que contenham categorias amplas de comportamento (Ramos et al., 2016).

Para auxiliar os servidores a terem êxito na descrição de competências, o facilitador das oficinas de mapeamento poderá utilizar diversos recursos didáticos. Entre os materiais didáticos amplamente empregados para o ensino de novos comportamentos, destacamos os materiais escritos, sejam impressos ou digitais. Visando melhorar a descrição das competências, foi desenvolvido um guia instrucional para auxiliar os servidores públicos a identificar e descreverem competências. A utilização de guias instrucionais pode ser empregada tanto como etapa substituta às oficinas de mapeamento de competências ou etapa complementar a elas. Assim, o presente estudo objetivou: 1) identificar e manipular fatores impactantes sobre a adesão ao procedimento de descrever competências utilizando um guia instrucional e 2) verificar a eficiência da utilização de um guia instrucional como material complementar para redução de condições problemáticas nas descrições de competências em oficinas de mapeamento de competências. Para isso, este trabalho foi subdividido em dois estudos.

\section{ESTUDO 1}

Embora diversos estudos tenham demonstrado a efetividade do modelo de gestão por competências (OCDE, 2010), ainda existem problemas para sua implantação (Henklain, Teixeira, Bastos, \& Lukiano, 2016). Entre eles, destaca-se o baixo engajamento por parte dos trabalhadores para a implantação da gestão de pessoas por competências (Henklain et al., 2016). Sendo esse um fator crítico, uma vez que os trabalhadores têm a responsabilidade de identificar, formular e avaliar as competências necessárias e existentes na organização, Henklain et al. (2016) e Brandão (2012) argumentam que a não adesão dos trabalhadores impacta diretamente sobre a efetividade do mapeamento das competências.

São inúmeros os fatores que influenciam uma pessoa a realizar ou não uma determinada atividade no ambiente de trabalho, abrangendo fatores políticos, sociais, econômicos, entre outros. Entre os fatores encontrados na literatura que podem impactar diretamente sobre a não realização de tarefas no contexto organizacional destacam-se: 1) Influência do gestor (Brandão, Borges-Andrade, \& Guimarães, 2012; Carbone et al., 2009); 2) Influência da equipe (Hamilton \& Owan, 2003); 3) Disponibilidade de recursos materiais (Mager \& Pipe, 2001); 4) Disponibilidade de tempo (Mager \& Pipe, 2001); 5) Clareza do que deveria ser feito (Mager \& Pipe, 2001) e 6) Importância/relevância da tarefa para o trabalhador (Munck et al., 2011).

Diante do exposto, o Estudo 1 objetivou 1) identificar os fatores que mais exercem influência sobre a adesão ao procedimento de descrever competências utilizando um guia instrucional e 2) manipular variáveis encontradas a partir dos fatores identificados.

\section{MÉTODO}

\section{Participantes}


Participaram do estudo 349 servidores públicos federais, integrantes de 15 oficinas de mapeamento de competências realizadas em três órgãos públicos federais, sendo dois ministérios e um tribunal regional eleitoral.

Os participantes foram selecionados pela área de Gestão de Pessoas dos órgãos em que o estudo foi realizado. Os órgãos foram orientados a selecionar servidores-chave que possuíam amplo conhecimento dos trabalhos e rotinas realizados nas unidades cujas competências seriam mapeadas.

\section{Instrumentos e materiais}

Foi elaborado um guia instrucional ${ }^{1}$ com orientações de como identificar e descrever as competências necessárias para a realização das atividades dos servidores em suas unidades de trabalho. As orientações para a descrição das competências, fornecidas no guia, foram formuladas com base nas proposições dos falsos objetivos de Botomé (1980) reformuladas por Franken (2009) e os cuidados metodológicos descritos por Brandão e Bahry (2005), Carbone et al. (2009) e Ramos et al. (2016) para a descrição de competências. Em consonância com esses pressupostos, o guia instruía que, ao descrever uma competência, dever-se-ia sempre iniciar por um verbo no infinitivo que designe uma ação observável, seguido de um objeto da ação e critérios de qualidade e condições de execução da ação. Em seguida, o guia apresentava, a título de cuidados metodológicos, seis elementos que deveriam ser evitados pelos servidores na descrição de competências. São eles: expressões amplas, vagas, contendo termos técnicos, designando categorias amplas de comportamento, declarações de intenção ou descrições de atividades.

O acesso dos servidores ao guia previamente às oficinas de mapeamento de competências permitiu avaliar o potencial desse guia como instrumento de ensino à distância do comportamento de descrever competências. Para isso, além do guia, foi elaborado um questionário com perguntas referentes a fatores que poderiam ter facilitado ou dificultado a descrição das competências antes da realização das oficinas, utilizando o guia instrucional. Os fatores investigados pelo questionário foram elaborados a partir dos achados de diversos autores da literatura que argumentam acerca de elementos que exercem influência sobre a realização de trabalhos no ambiente organizacional (Brandão, 2012; Brandão et al., 2012; Carbone et al., 2009; Hamilton \& Owan, 2003; Mager \& Pipe, 2001; Munck et al., 2011; Pantoja \& Borges-Andrade, 2009). Os fatores investigados pelo questionário englobaram: 1) Facilidade de acesso ao guia; 2) Suficiência das informações do guia para a elaboração das competências; 3) Facilidade de compreensão do conteúdo; 4) Tempo disponível para elaboração da atividade; 5) Sobrecarga com outros serviços; 6) Apoio da chefia; 7) Trabalho em equipe; 8) Acesso à docu- mentação para elaboração das competências; 9) Comunicação entre a equipe e; 10) Avaliação de que a atividade não teria importância. Os participantes responderam as questões, indicando se concordavam ou discordavam de afirmações relacionadas aos itens 1 a 10 acima listados.

Para realizar as análises estatísticas dos dados foi utilizando o software IBM SPSS Statistics 25.

\section{Ambiente}

O Estudo foi realizado em três instituições públicas brasileiras que se encontravam em fase inicial do processo de implantação do modelo de Gestão por Competências. Os questionários foram preenchidos em auditórios e salas localizadas nos órgãos, durante oficinas de mapeamento da organização, tanto na sede dos órgãos quanto em superintendências regionais em diversas unidades federativas do Brasil.

\section{Procedimento}

Para investigar quais fatores poderiam influenciar a adesão dos servidores ao procedimento de descrever competências, utilizando um guia instrucional antes das oficinas, as seguintes etapas foram executadas.

Foi enviado um e-mail aos participantes junto com o guia instrucional, solicitando aos participantes que elaborassem as competências necessárias para a realização das atividades de suas unidades com base nas instruções descritas no guia. O tempo de antecedência da disponibilização do guia variou entre dois dias úteis (quatro dias corridos) e vinte e um dias úteis (trinta dias corridos). A partir das informações presentes no guia, os servidores deveriam descrever quais competências que são necessárias para a realização do trabalho no setor que o servidor estava representando.

No dia da oficina, foram identificados os servidores que elaboraram e quais não elaboraram descrições de competências a partir do guia. Essas descrições de competências foram coletadas. Em seguida, foi entregue o questionário aos participantes da oficina, com orientações para o preenchimento dos questionários com a maior fidedignidade possível, identificando que fatores auxiliaram ou prejudicaram a elaboração das competências antes da oficina. Todos os participantes, tanto os que elaboraram as competências antes das oficinas, quanto os que não elaboraram as competências, receberam o questionário.

\section{Análise de dados}

A busca por fatores potencialmente influenciadores da adesão à realização da tarefa de descrever competências utilizando um guia instrucional foi realizada com base na investigação de possíveis diferenças entre os padrões de respostas dos questionários. Foram comparados os resulta- 
dos dos servidores que entregaram o material solicitado (descrição prévia de competências com base na leitura do guia), Grupo $A$, com aqueles que não entregaram o material, Grupo B, analisando a diferença entre as respostas dos dois grupos por meio do teste $U$ de Mann-Whitney.

Em oficinas seguintes, o fator "disponibilidade de tempo" foi avaliado diretamente, mensurando o efeito da antecedência de tempo da disponibilização do guia sobre a elaboração das competências antes das oficinas. Para isso, foi considerada a entrega ou não entrega das competências descritas até a data da oficina e o tempo de antecedência que o guia foi disponibilizado junto à solicitação para realização da tarefa. Os dados obtidos a partir da manipulação do tempo foram analisados, identificando a existência ou não de uma correlação entre o tempo disponibilizado e a entrega dos materiais, utilizando o coeficiente de correlação de postos de Spearman.

\section{Resultados e discussão}

Dos 349 questionários analisados, 73 foram de participantes que entregaram o material solicitado até a data das oficinas, 143 que não realizaram a entrega solicitada e 134 questionários foram invalidados devido ao não preenchimento das informações básicas ou a substituição dos participantes no dia da oficina, impossibilitando ao participante presente na oficina ter tido acesso ao guia enviado pelo experimentador.

Foi avaliada a concordância dos grupos em cada fator apresentado no questionário. Os resultados foram comparados, identificando os fatores que apresentaram maiores diferenças entre os grupos. A partir dos resultados, foi aplicado o teste U de Mann-Whitney comparando os fatores. Os resultados indicam que não existem diferenças significativas na média entre os dois grupos quanto à concordância com os fatores $1,2,5,7,8$ e 9 e existem diferenças significativas entre os grupos quanto à concordância com os fatores $3,4,6$ e 10.

Na Figura 1, estão representados os resultados dos fatores que apresentaram diferenças significativas entre as respostas dos questionários dos servidores que entregaram o material solicitado e os que não entregaram. Os dados apresentam a diferença na porcentagem de respostas de cada grupo, subtraindo a porcentagem das respostas do Grupo B da porcentagem das respostas do Grupo A.

O tempo disponibilizado para elaboração da tarefa (Fator 4) foi o fator que apresentou maior diferença na percepção entre os dois grupos. Entre os participantes do Grupo A, $83,5 \%$ concordaram que o tempo foi suficiente, contra $70,2 \%$ de concordância no Grupo B, gerando uma diferença de 13,3\% na concordância entre os grupos.
Figura 1. Diferenças entre a concordância dos participantes que não entregaram e que entregaram os materiais antes das oficinas. $O$ Eixo $Y$ apresenta as perguntas referentes aos fatores que impactaram na realização da tarefa e o Eixo $X$ a diferença da porcentagem de concordância entre os dois grupos.

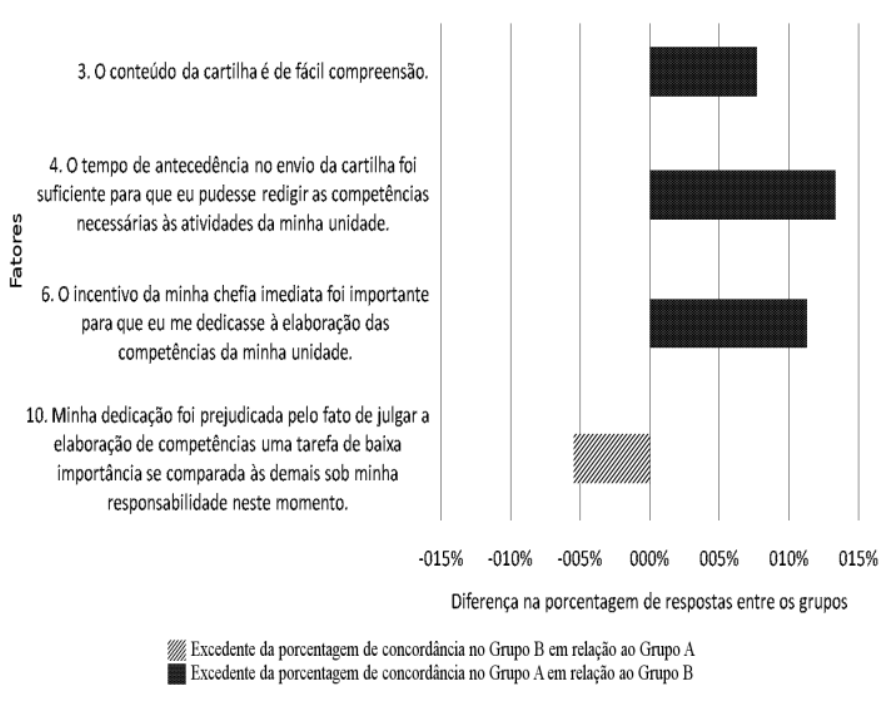

O incentivo da chefia para elaboração das competências (Fator 6), apresentou $11,3 \%$ de diferença na percepção dos servidores entre os dois grupos. Dos participantes do Grupo A, $90,41 \%$ concordaram que o incentivo da chefia foi importante para elaboração das competências contra $79,13 \%$ de concordância do Grupo B.

A percepção dos servidores acerca da facilidade de compreensão do guia (Fator 3) apresentou $7,7 \%$ de diferença na concordância entre a média dos dois grupos. Entre os participantes do Grupo A, 94,4\% concordaram que as informações do guia eram de fácil compreensão. No Grupo B a concordância entre os participantes foi de $86,7 \%$.

A percepção dos servidores acerca da importância da atividade de elaborar competências antes das oficinas (Fator 10) apresentou uma diferença de $5,5 \%$ entre a média dos grupos. Dos participantes do Grupo A, 10,9\% concordaram que tiveram a dedicação prejudicada por considerar a tarefa de baixa importância frente a outras atividades e $16,4 \%$ dos participantes do Grupo B concordaram com essa afirmativa. Os outros fatores investigados não possuíram significância estatística entre os grupos.

A avaliação da influência do tempo de antecedência da disponibilização dos guias sobre a entrega da descrição de competências dos participantes é apresentada na Figura 2. Os resultados obtidos por meio da comparação entre quantidade de tempo disponibilizada aos participantes para elabo- 
rarem as competências, em dias úteis, e a quantidade de participantes que entregaram as competências são correlacionadas.

Figura 2. Relação entre tempo disponibilizado para realizar as atividades e entregas. $O$ Eixo $Y$ apresenta a quantidade de dias úteis disponibilizados para os participantes elaborarem as competências e o Eixo $X$ a porcentagem de participantes que elaboraram as competências em cada grupo.

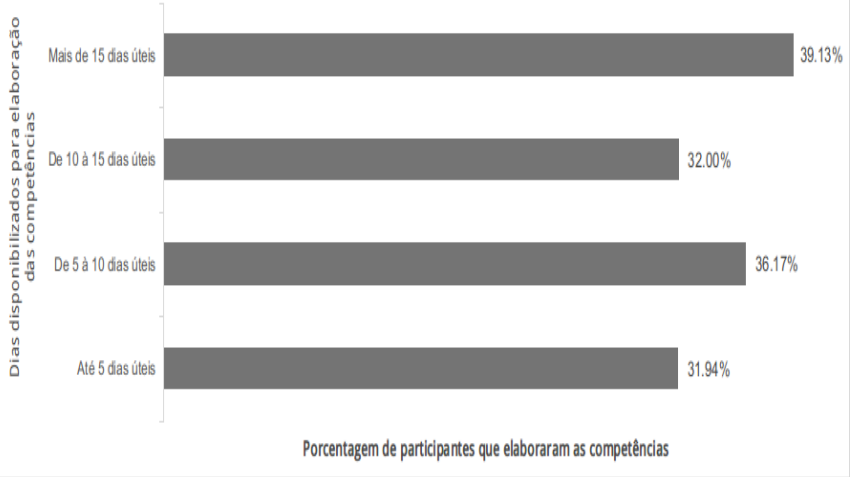

Os resultados demonstraram uma fraca correlação entre o tempo de antecedência de envio do guia e a porcentagem de participantes que elaboravam as competências antes das oficinas $^{2}$. A influência da disponibilidade de tempo para a realização da tarefa de elaborar e descrever competências, indicada pelos participantes como um fator de elevado impacto, não foi estatisticamente confirmada como uma variável com influência significativa para a realização da tarefa proposta. Tais resultados refutam a hipótese levantada com a aplicação do questionário, que indicou o tempo como a variável mais relevante para a elaboração das competências antes de oficinas. Esses resultados parecem indicar uma inconsistência entre o fazer e o dizer dos participantes. A disponibilidade de tempo não parece estar diretamente correlacionada com o número de entregas dos grupos.

Os resultados obtidos por meio do questionário, investigando fatores impactantes para a adesão à tarefa de descrever competências, comparam a opinião dos servidores que entregaram e não entregaram o material solicitado. Embora o relato dos servidores forneça informações importantes, nem sempre o que o indivíduo diz será correspondente ao que ele fez. $O$ indivíduo pode alegar que se comportou de determinada forma e apresentar argumentos que não correspondem aos que realmente exerceram controle sobre seu comportamento. Isso é intensificado quando o ouvinte não tem acesso aos eventos relatados pelo falante (Stocco, Thompson, \& Hart, 2014). Assim, o servidor poderia ter considerado que atribuir o fator "insuficiência de tempo disponibilizado para realizar tarefa" como uma resposta cuja probabilidade de gerar consequências negativas seria menor do que responder que não elaborou a tarefa por considerar que a atividade possuía pouca importância frente a outras atividades.

Uma hipótese para a inconsistência encontrada entre o dizer e o fazer é que os participantes poderiam se sentir mais ou menos confortáveis em concordarem com determinados fatores como justificativas para a forma como se comportam (De Rose, 1999). Assim, mesmo que as respostas não tenham sido consequenciadas com estímulos reforçadores ou punidores específicos pelo experimentador, os participantes podem ter julgado que certos fatores são mais justificáveis socialmente, do que outros, para explicar as causas de seus comportamentos. Exemplificando, os servidores poderiam julgar que um argumento alegando falta de tempo como causa para a não realização da tarefa seria uma resposta mais aceitável do que responder que achou a tarefa sem importância, mesmo que os questionários mantivessem o anonimato dos participantes.

Os resultados apresentados neste estudo são de caráter exploratório, identificando, por meio da opinião dos participantes (e por análises de consistência dessas opiniões entre grupos que apresentaram e que não apresentaram o comportamento esperado), os fatores mais impactantes na tarefa de descrever competências antes das oficinas, com a utilização de um guia instrucional. Estes achados poderão ser utilizados como norteadores de futuros estudos, que poderão manipular experimentalmente diversas variáveis decorrentes dos fatores identificados. Tais estudos poderão investigar a correspondência fazer-dizer, aceitando ou rejeitando os fatores levantados neste estudo. A manipulação destes fatores e avaliação do impacto de cada um sobre o comportamento de elaborar as competências, antes das oficinas, poderá avaliar quanto cada um dos fatores influencia na elaboração de competências.

\section{ESTUD0 2}

Ao avaliar a adesão ao procedimento de descrever competências, também é importante considerar a qualidade da descrição. A descrição de competências é um fator essencial para uma efetiva gestão de pessoas, visto que repercute sobre as demais etapas desse modelo de gestão, consequentemente, sobre as decisões nos demais subsistemas da gestão de pessoas. Apesar das implicações que a descrição de competências possui na implantação da gestão por competências, pouca atenção tem sido dada a esta etapa do mapeamento (Ramos et al., 2016).

Nem sempre formular competências é uma tarefa simples. Desta forma, muitos problemas na descrição de competências podem ocorrer durante a sua formulação. Em um estudo realizado por Ramos et al. (2016), os autores avaliaram a descrição de competências com base nas categorias 
de falsos objetivos, propostas por Botomé (1980) e reformuladas por Franken (2009) e alguns cuidados metodológicos apontados na literatura identificando problemas na formulação de competências. Os resultados indicaram que apenas $6,8 \%$ das competências descritas, durante as oficinas, foram redigidas sem nenhuma condição problemática.

Aplicar os cuidados apontados no contexto de ensino para o contexto organizacional quanto a descrição de competências pode melhorar essas descrições (Ramos et al., 2016), considerando que assim se pode nortear a elaboração das competências especificando com maior clareza e objetividade os comportamentos que o servidor deve emitir.

Neste contexto, materiais instrucionais podem ser utilizados como ferramentas para auxiliar na descrição de competências uma vez que fornecem informações acerca da metodologia para essa tarefa. Entretanto, ainda não foi empiricamente estudado e aferido o impacto do uso desses materiais na potencial melhora da qualidade do trabalho desenvolvido em oficinas. Assim, o presente estudo objetivou comparar a qualidade das competências descritas nas seguintes condições: 1) Competências formuladas a partir das oficinas de mapeamento de competências; 2) Competências formuladas com a utilização do guia instrucional e; 3) Competências formuladas com a utilização do guia instrucional e oficina de mapeamento.

\section{MÉTODO}

\section{Participantes}

Participaram deste estudo 291 servidores de dois ministérios integrantes de oficinas de mapeamento de competências. Os participantes foram selecionados pela área de Gestão de Pessoas dos órgãos em que o estudo foi realizado. Cada órgão foi orientado a selecionar servidores-chave que possuíam amplo conhecimento dos trabalhos e rotinas realizados nas unidades cujas competências seriam mapeadas, conforme descrito no estudo 1.

\section{Instrumentos e materiais}

Foi utilizado o guia "Elaboração de Competências na Administração Pública"1 , descrito no Estudo 1.

\section{Ambiente}

O Estudo 2 foi realizado em duas instituições públicas brasileiras que se encontravam na fase inicial do processo de implantação do modelo de Gestão de Pessoas por Competências. A coleta de dados ocorreu em salas ou auditórios dos órgãos em que o mapeamento foi realizado.

\section{Procedimento}

0 instrumento auxiliar foi disponibilizado, via e-mail institucional, aos participantes das unidades que comporiam oficinas de mapeamento de competências. Os participantes das oficinas receberam instruções acerca do material e foram solicitados a identificar e descrever as competências de suas respectivas unidades até o prazo estabelecido. 0 material elaborado poderia tanto ser enviado por e-mail ao pesquisador, quanto poderia ser entregue no primeiro dia da oficina.

As fases específicas que compunham o Estudo 2 serão descritas a seguir.

\section{Fase 1 - Oficinas de mapeamento de competências}

As oficinas foram conduzidas em duas etapas ao longo de dois dias, com duração de até seis horas diárias. A primeira etapa foi uma apresentação oral, com a utilização slides, na qual um facilitador experiente realizou uma breve apresentação do Projeto de Mapeamento de Competências e suas implicações na gestão de pessoas. Posteriormente, o facilitador instruiu os participantes acerca de como elaborar e descrever as competências de suas unidades, expondo o método utilizado e os cuidados necessários para a identificação e descrição das competências, conforme as orientações de Brandão (2012), reformuladas por Ramos (2015). As informações repassadas pelo facilitador consistiram nas mesmas informações descritas no guia enviado anteriormente aos participantes, com pequenas alterações. A palestra inicial teve a duração de aproximadamente quarenta minutos.

$\mathrm{Na}$ segunda etapa das oficinas, os participantes identificaram e descreveram as competências conforme as orientações fornecidas na palestra. Durante as oficinas, um grupo de facilitadores auxiliava os participantes na elaboração das competências, orientando e sanando suas dúvidas. A quantidade de facilitadores em cada oficina variou conforme o número de participantes, com uma média de um facilitador para cada dez servidores.

Os participantes que já haviam elaborado previamente as competências, utilizando o guia instrucional, deveriam revisar e complementar a descrição de competências, com o auxílio dos facilitadores. Os participantes que não haviam elaborado as competências utilizando o material instrucional disponibilizado antes das oficinas tiveram o trabalho de elaborar e descrever todas as competências de suas unidades durante as oficinas.

\section{Fase 2 - Análise das descrições das competências}

Para análise de dados, as descrições de competências produzidas pelos participantes foram subdivididas em quatro grupos (ver Tabela 1): 1) Grupo A, composto pelo material entregue pelos participantes que já haviam elaborado previ- 
amente as competências, antes das oficinas de mapeamento, utilizando o guia instrucional e complementaram ou reelaboraram a descrição das competências durante as oficinas; 2) Grupo B, composto pelo material dos participantes das oficinas que não haviam elaborado previamente as competências antes das oficinas, mas receberam a solicitação e o guia instrucional para a descrição de competências; 3) Grupo C, composto pelo material dos participantes substitutos nas oficinas. Este grupo foi convocado pela gestão de pessoas para substituírem os servidores inicialmente convocados que não puderam comparecer no dia das oficinas. Este grupo não teve contato prévio com o guia instrucional, consequentemente, não produziu nenhum material antes das oficinas e; 4) Grupo A2, corresponde ao material elaborado por uma parcela dos participantes Grupo A, antes das oficinas de mapeamento de competências. Assim, essas formulações de competências foram elaboradas pelos participantes apenas com a utilização do guia instrucional, sem o efeito da participação dos servidores em oficinas de mapeamento.

Os produtos finais entregues pelos participantes foram comparados, analisando as diferenças na qualidade da descrição das competências entre os quatro grupos. Para isso, foi avaliada a ocorrência de seis condições problemáticas com base nas orientações descritas em Ramos et al. (2016), com algumas modificações. As seis condições problemáticas avaliadas foram:

1. Ausência de Verbo e Objeto de Ação Observáveis: Competências descritas sem um verbo e um objeto de ação que sejam passíveis de observação. e.g. "conhecer técnicas de vendas".

2. Excesso de Verbos e/ou Complementos: Descrição de competência com excesso de verbos e/ou complementos que não são complementares entre si, indicando comportamentos distintos, e.g. "Planejar, implementar e fiscalizar os projetos de desenvolvimento de sistemas, utilizando a metodologia estabelecida".
3. Categorias Amplas de Comportamento: Utilização de verbos que podem designar diversos comportamentos distintos, sem especificação do que o indivíduo deve ser capaz de fazer de maneira clara, e.g., auxiliar, ajudar, apoiar. e.g.: "Auxiliar o ministro nas atividades da unidade".

4. Declaração de Intenção: Presença de intenções ou garantias que não depende apenas da pessoa que possui a competência, e.g. "Atender os clientes, oferecendo os produtos da organização, garantindo que eles fiquem plenamente satisfeitos".

5. Ausência de Complementos: Competência descrita sem nenhum complemento seja uma condição na qual a competência é executada ou um critério de como deve ser executada e.g: "Elaborar documentos".

6. Utilização de Termos Técnicos: Uso de termos técnicos, estrangeirismos ou siglas na descrição da competência, e.g: "Elaborar o PDTI, utilizando o SISCAD”.

\section{Análise de dados}

Das 4.385 competências descritas durante as oficinas de mapeamento dos órgãos, 430 competências foram selecionadas de maneira aleatória e analisadas, que é amostra significativa a um nível de confiança de $95 \%$ e erro amostral máximo de 5\%. Adicionalmente, foi analisado um total de 114 competências dos materiais produzidos antes da oficina de Mapeamento de Competências, seguindo as instruções do Guia de Mapeamento de Competências, totalizando um montante de 544 competências analisadas, juntando competências elaboradas antes e após as oficinas.

Para avaliar se houve diferença significativa entre os quatro grupos de dados foi aplicado o teste não paramétrico Kruskal-Wallis, comparando a quantidade de condições problemáticas encontradas nas competências dos diferentes grupos.

Resultados e discussão

\begin{tabular}{|c|c|c|c|c|}
\hline Grupo & Participantes & $\begin{array}{l}\text { Recebimento do } \\
\text { Guia }\end{array}$ & $\begin{array}{l}\text { Elaboração das compe- } \\
\text { tências com base no guia }\end{array}$ & $\begin{array}{l}\text { Participação nas } \\
\text { oficinas }\end{array}$ \\
\hline Grupo A & 58 & Sim & Sim & Sim \\
\hline Grupo B & 104 & Sim & Não & Sim \\
\hline Grupo C & 129 & Não & Não & Sim \\
\hline Grupo A2 & Equivalente ao Grupo A & Sim & Sim & Não \\
\hline
\end{tabular}


Os resultados apresentados na Tabela 2 demonstram a ocorrência das condições problemáticas nas 544 competências analisadas nos quatro grupos.
2) ausência de complementos e 3) categorias amplas de comportamento. As menos recorrentes foram descrições com: 1) Declarações de intenção e

Tabela 2. Total de ocorrência de condições problemáticas por grupo

\begin{tabular}{|c|c|c|c|c|c|}
\hline & & & $\begin{array}{l}\text { Com condições } \\
\text { problemáticas }\end{array}$ & \multicolumn{2}{|c|}{ Sem condição problemática } \\
\hline Grupo & Condições avaliadas & Total & $\begin{array}{l}\text { Média de condições } \\
\text { problemáticas por } \\
\text { competência }\end{array}$ & Total & Percentual \\
\hline Grupo A & 177 & 57 & 0,322 & 130 & $73 \%$ \\
\hline Grupo B & 177 & 59 & 0,333 & 122 & $69 \%$ \\
\hline Grupo C & 76 & 27 & 0,355 & 54 & $71 \%$ \\
\hline Grupo A2 & 114 & 103 & 0,903 & 42 & $37 \%$ \\
\hline
\end{tabular}

A partir dos resultados do teste de Kruskal-Wallis foram constatadas diferenças significativas na média de condições problemáticas por competência entre pelo menos um dos grupos. As comparações post hoc mostram o Grupo A2 como o único que apresentou resultados destoantes dos demais, apresentando diferenças significativas na média de erros por competência se equiparado aos demais grupos (Tabela 3 ).

A Tabela 4 apresenta o número de ocorrência das condições problemáticas, separadas por categoria, encontradas nas competências descritas pelos participantes dos quatro grupos. Em média, as condições problemáticas mais comuns foram as descrições com: 1) Utilização de termos técnicos,
2) ausência de verbo e objeto de ação observáveis.

Os participantes que formularam previamente as competências utilizando o guia e participaram das oficinas, realizaram a descrição de competências com menos termos técnicos que os grupos que apenas participaram das oficinas. Entretanto, utilizaram excesso de verbos/complementos em maior proporção se comparado aos grupos que apenas participaram das oficinas. Pouca diferença foi observada entre os Grupos A, B e C na maioria das outras condições problemáticas. Entretanto, o Grupo A2 apresentou resultados destoantes dos demais em diversas condições problemáticas.

Tabela 3. Diferenças entre os grupos em comparação post hoc.

\begin{tabular}{|c|c|c|c|}
\hline Comparação entre os grupos & Sig. & $\begin{array}{l}\text { Sig. } \\
\text { Ajust. }\end{array}$ & Resultado \\
\hline "Grupo A" comparado com "Grupo C" & 695 & 1,000 & $\begin{array}{l}\text { Sem diferenças } \\
\text { significativas }\end{array}$ \\
\hline "Grupo A" comparado com "Grupo B" & ,526 & 1,000 & $\begin{array}{l}\text { Sem diferenças } \\
\text { significativas }\end{array}$ \\
\hline "Grupo A" comparado com “Grupo A2" & ,000 & 000 & $\begin{array}{l}\text { Significativamente } \\
\text { diferente }\end{array}$ \\
\hline "Grupo C" comparado com “Grupo B" & 921 & 1,000 & $\begin{array}{l}\text { Sem diferenças } \\
\text { significativas }\end{array}$ \\
\hline "Grupo C" comparado com "Grupo A2" & ,000 & 000 & $\begin{array}{l}\text { Significativamente } \\
\text { diferente }\end{array}$ \\
\hline "Grupo B" comparado com "Grupo A2" & ,000 & 000 & $\begin{array}{l}\text { Significativamente } \\
\text { diferente }\end{array}$ \\
\hline
\end{tabular}

Nota: O nível de significância é de 0,05. Valores de significância foram ajustados pela correção de Bonferroni para múltiplos testes. 
Os dados obtidos mostram que o guia instructional aqui utilizado foi pouco eficiente na redução do número de condições problemáticas na descrição de competências. A adição do guia instructional como etapa preliminar à identificação e aperfeiçoamento de instrumentos como o guia instrucional pode contribuir para um melhor aproveitamento deste tempo. Além disso, pode contribuir para a redução da centralidade das oficinas de mapeamento dentro do processo de implantação da gestão por competências. Os dados aqui relatados

Tabela 4. Ocorrência das seis condições problemáticas entre os quatro grupos analisados

\begin{tabular}{|c|c|c|c|c|}
\hline Grupo & Participantes & $\begin{array}{l}\text { Recebimento do } \\
\text { Guia }\end{array}$ & $\begin{array}{l}\text { Elaboração das compe- } \\
\text { tências com base no guia }\end{array}$ & $\begin{array}{l}\text { Participação nas } \\
\text { oficinas }\end{array}$ \\
\hline Grupo A & 58 & Sim & Sim & Sim \\
\hline Grupo B & 104 & Sim & Não & Sim \\
\hline Grupo C & 129 & Não & Não & Sim \\
\hline Grupo A2 & Equivalente ao Grupo A & Sim & Sim & Não \\
\hline
\end{tabular}

descrição de competências mostrou pouco impacto

sobre a qualidade da entrega final. Essa afirmação está baseada na comparação da qualidade do produto entregue pelos participantes que elaboraram e os que não elaboraram as competências antes das oficinas. Adicionalmente, foram identificadas com maior frequência e em maior percentual condições problemáticas nas competências que foram formuladas com base no guia e comparadas com as competências formuladas com a participação em oficinas de mapeamento de competências.

Apesar disso, os dados não permitem generalizar que guias instrucionais não sejam efetivos para o desenvolvimento de comportamentos como o aqui em tela, notadamente a descrição de competências. É possível que características do próprio guia tenham determinado esse baixo impacto. 0 guia era essencialmente informativo e não ofereceu oportunidades de os servidores se comportarem e se exporem a feedback para esses comportamentos. Ele não lança mão, por exemplo, do conhecimento tradicional em Análise do Comportamento sobre instrução programada ou outras tecnologias do ensino (Skinner, 1972). Instrução programada, mesmo em se tratando de material impresso, fornece oportunidades de o leitor preencher lacunas ou responder a perguntas, com feedback imediato sob a forma de apresentação da resposta correta, por exemplo, no verso da página. É possível que um guia instrucional sob a forma de instrução programada pudesse produzir maior impacto como uma ferramenta de ensino nas condições descritas no presente estudo. Adicionalmente, poderia ser avaliada uma versão eletrônica do guia instrucional que incorporasse técnicas de instrução programada incluindo feedback imediato para respostas do aprendiz. Pesquisas subsequentes devem explorar essas possibilidades.

A tarefa de descrever as competências não é simples e rápida, podendo requisitar muito tempo dos servidores. 0 mostram que a efetividade do mapeamento de competências ainda é muito dependente da participação de servidores nessas oficinas presenciais. Esse é um elemento gerador de dificuldade de disseminação ampla do modelo de gestão por competências na administração pública brasileira, visto que a realização de oficinas presenciais constitui elevado custo de tempo e dinheiro. Pesquisas subsequentes devem explorar o aperfeiçoamento de guias e outros instrumentos para impulsionar a participação dos servidores e melhorar a qualidade do produto de sua participação, com menor engajamento presencial.

Embora os dados deste estudo não demonstrem efetividade do guia instrucional como ferramenta auxiliar para a redução do número de condições problemáticas nas descrições de competências durante oficinas de mapeamento, ainda são necessários estudos que investiguem a efetividade do guia para a redução do tempo utilizado pelos servidores para essa atividade. É possível que o guia aqui utilizado tenha tido impacto sobre a redução do tempo de dedicação dos servidores nas oficinas. A redução da duração das oficinas por si só já seria um importante impacto da utilização de guias instrucionais, uma vez que elas demandam muito recurso. Assim, implementar ferramentas adicionais para reduzir o tempo que servidores dedicam em oficinas de mapeamento de competências pode tornar a implantação da gestão por competências menos onerosa. Futuros estudos devem investigar se a elaboração prévia de competências realizadas com base em um guia instrucional pode reduzir o tempo para a descrição de competências em oficinas.

Uma possível limitação do presente estudo está no fato de que o menor número de condições problemáticas no produto final das oficinas de mapeamento pode ter sido em parte determinado pelo auxílio dos facilitadores durante a segunda etapa das oficinas de mapeamento de competências. Naquela etapa, a equipe de facilitadores atuava sanando 
as dúvidas dos servidores e revisando as competências formuladas. Futuros estudos poderão investigar possibilidades de inclusão desse tipo de interação em materiais instrucionais, como já discutido acima.

\section{CONSIDERAÇÕES FINAIS}

O modelo de gestão de pessoas por competências tem demonstrado bons resultados no setor público internacional, possibilitando a identificação de parâmetros para mensurar os comportamentos necessários aos trabalhadores para a realização de seu trabalho de maneira eficiente (OCDE, 2010). Embora esse modelo de gestão seja apontado pela literatura como um modelo promissor, ainda existem desafios para sua efetiva implantação (Henklain et al., 2016). Entre as dificuldades que podem ser encontradas para implantação da gestão de pessoas por competências, analisamos, neste trabalho, a adesão dos servidores à descrição de competências, utilizando um guia instrucional como ferramenta auxiliar no mapeamento de competências. Apesar da importância da colaboração dos servidores para a descrição das competências e dos impactos causados pela falta de engajamento de parte dos servidores do órgão, pouco tem sido pesquisado sobre o assunto (Ramos et al., 2016).

Os dados obtidos neste estudo sugerem que a elaboração prévia de competências, por meio de um guia instrucional meramente informativo, não alterou significativamente o produto final obtido nas oficinas. Mesmo que o guia instrucional e a palestra ministrada nas oficinas de mapeamento contivessem as mesmas informações, a oficina é uma ocasião muito mais rica de oportunidades de responder e produzir feedback, e acesso a instrução adicional. Essas características devem ser incorporadas ao guia instrucional, sob a forma de instrução programada ou a uma versão eletrônica com ainda mais recursos que permitam ao servidor obter feedback instrucional.

Adicionalmente, os resultados demonstraram que fatores indicados pelos servidores como muito impactantes sobre a adesão à tarefa de descrever competências podem ser inconsistentes com os fatores que realmente controlam seus comportamentos. A contradição identificada na quantidade de tempo disponibilizada evidencia essa inconsistência entre o dizer e o fazer. Entretanto, investigações acerca do impacto dos demais fatores ainda são necessárias. Por fim, como um estudo exploratório e pioneiro na busca sistemática de fatores que impactam na adesão de servidores na descrição de competências, o presente estudo proporciona um eixo norteador para futuras pesquisas que investiguem os fatores e intervenções para melhorar a adesão dos servidores em projetos de gestão de pessoas.
Esses achados contribuem para preencher a lacuna decorrente da pouca atenção que tem sido dada para o engajamento dos servidores na descrição das competências que subsidiarão as demais etapas do processo de implantação do modelo de Gestão por Competências. Novos estudos são necessários para aprimorar os métodos e técnicas que contribuam com o aperfeiçoamento da etapa de identificar e descrever competências, assim como maneiras para melhorar o engajamento dos servidores nesta etapa do mapeamento de competências.

\section{DECLARAÇÃO DE FINANCIAMENTO}

A pesquisa relatada no manuscrito foi financiada parcialmente pela bolsa de mestrado do primeiro autor (CAPES, Número do Processo: 1540963).

\section{DECLARAÇÃO DA CONTRIBUIÇÃO DOS AUTORES}

Certificamos que todos os autores participaram suficientemente do trabalho para tornar pública sua responsabilidade pelo conteúdo. A contribuição de cada autor pode ser atribuída como se segue:

Todos autores contribuíram com o planejamento do estudo e a coleta de dados. Barth, com auxilio de Ramos e Barros realizou a redação inicial do estudo. Barth contribuiu com a análise dos dados coletados. Todos autores contribuíram com a revisão e a redação final do artigo.

\section{DECLARAÇÃO DE CONFLITOS DE INTERESSE}

Os autores declaram que não há conflitos de interesse no manuscrito submetido.

\section{AGRADECIMENTOS}

Os autores agradecem a Equipe do Laboratório de Gestão do Comportamento Organizacional pelo auxilio durante as oficinas de mapeamento de competências e o Prof. Aécio Borba pelas considerações realizadas para melhorias no trabalho.

\section{REFERÊNCIAS}

Bohlouli, M., Mittas, N., Kakarontzas, G., Theodosiou, T., Angelis, L., \& Fathi, M. (2017). Competence assessment as an expert system for human resource management: A mathematical approach. Expert Systems with Applications, 70(3), 83-102. 
Botomé, S. P. (1980). Objetivos comportamentais no ensino: a contribuição da análise experimental do comportamento. Tese de Doutorado. Universidade de São Paulo, São Paulo.

Brandão, H. P. (2012). Mapeamento de competências: Métodos, técnicas e aplicações em gestão de pessoas ( $1^{\mathrm{a}}$ ed). São Paulo: Editora Atlas.

Brandão, H. P., \& Bahry, C. P. (2005). Gestão por Competências: Métodos e técnicas para mapeamento de competências. Revista do Serviço Público, 56(2), 179-194. https://doi.org/10.21874/rsp.v56i2.224.

Brandão, H. P., Borges-Andrade, J. E., \& Guimarães, T. A. (2012). Desempenho organizacional e suas relações com competências gerenciais, suporte organizacional e treinamento. Revista de Administração, 47(4), 523-539. http://dx.doi.org/10.5700/rausp1056

Carbone, P. P., Brandão, H. P., Leite, J. B. D., \& Vilhena, R. M. P. (2009). Gestão por Competências e Gestão do Conhecimento ( $3^{\mathrm{a}}$ ed). Rio de Janeiro: Editora Fundação Getúlio Vargas.

De Rose, J. C. (1999). O relato verbal segundo a perspectiva da análise do comportamento: contribuições conceituais e experimentais. Em: R. A. Banaco (Org). Sobre comportamento e cognição: Aspectos teóricos, metodológicos e de formação em análise do comportamento e terapia cognitiva, 1. São Paulo: Arbytes.

Franken, V. J. (2009). Avaliação da formação específica do psicólogo organizacional e do trabalho a partir daquilo que está proposto nos planos de ensino de disciplinas relacionadas ao seu campo de atuação profissional. Dissertação de Mestrado. Universidade Federal de Santa Catarina, Florianópolis.

Hamilton, B. H., \& Owan, J. A. N. H. (2003) Team Incentives and Worker Heterogeneity: An Empirical Analysis of the Impact of Teams on Productivity and Participation. Journal of Political Economy, 111(3), 465-497. https://doi.org/10.1086/374182

Henklain, M. H. O., Teixeira, R. F., Bastos, A. E., \& Lukiano, V. (2016). Obstáculos e benefícios na implantação do modelo de gestão por competências: A percepção de consultores de Recursos Humanos. Revista Eletrônica Gestão e Serviços, $\quad 7(1), \quad 1441-1465$ http://dx.doi.org/10.15603/2177-7284/regs.v7n1p14411461
Mager R. F., \& Pipe, P. (2001) Analisando Problemas de Performance ( $1^{\mathrm{a}}$ ed). São Paulo: Market Books Brasil.

Munck, L., Munck, M. G. M., \& Borim-de-Souza, R. (2011) Gestão de pessoas por competências: análise de repercussões dez anos pós-implantação. Revista de Administração da Mackenzie - RAM, 12(1), 4-52. http://dx.doi.org/10.1590/S1678-69712011000100002.

OCDE - Organização para a Cooperação e Desenvolvimento Econômico (2010) Avaliação da Gestão de Recursos Humanos no Governo - Relatório da OCDE. Éditions OCDE.

Pantoja, M. J., \& Borges-Andrade. J. E. (2009) Estratégias de Aprendizagem no Trabalho em Diferentes ocupações Profissionais. Revista de Administração Contemporânea Eletrônica, 3(1), 41-62. Recuperado de http://www.anpad.org.br/periodicos/arq_pdf/a_833.pdf

Pinto, M. C. F., \& Silva, F. M. (2015). Gestão de Pessoas na Administração Pública Brasileira: uma análise sobre sua evolução histórica e o atual contexto em transformação. Revista Eletrônica do TCE-RS, 2(1) 1-16.

Ramos, C. C. (2015). Aplicação do Procedimento de Decomposição Comportamental para a Descrição de Competências no Contexto Público Federal. Tese de Doutorado. Universidade Federal do Pará, Belém. Recuperado de http://ppgtpc.propesp.ufpa.br/ARQUIVOS/teses/Camila\% 20Ramos\%202015.pdf

Ramos, C. C., Costa, T. D., Borba, A. V., \& Barros, R. S. (2016). Uma abordagem comportamental para a descrição de competências em uma instituição pública federal. Perspectivas em Análise do Comportamento, 7(1), 133-146. http://dx.doi.org/10.18761/pac.2015.029

Siqueira, M. V. S., \& Mendes, A. M. (2009). Gestão de pessoas no setor público e a reprodução do discurso do setor privado. Revista do Serviço Público, 60(3), 241-250. http://dx.doi.org/10.21874/rsp.v60i3.25

Skinner, B. F. (1972). Tecnologia do Ensino. São Paulo: Herder e Edusp.

Skinner, B. F. (2014). Science and human behavior. New York: The Free Pass (Obra original publicada em 1953). 
Stocco, C. S., Thompson, R. H., \& Hart, J. M. (2014) Teaching Tacting of Private Events Based on Public Accompaniments: Effects of Contingencies, Audience Control, and Stimulus Complexity. Analysis Verbal Behavior, 30, 1-19. https://doi.org/10.1007/s40616-014-0006-y

\section{NOTAS}

1. Guia institucional disponível em: https://www.gestcompesquisas.com/publicacoes

2. A partir da aplicação do coeficiente de correlação de postos de Spearman, identificou-se um coeficiente de correlação positivo fraco $(0,191)$ entre o tempo disponibilizado e a entrega da descrição das competências até a data das oficinas. Entretanto, sem significância estatística a um grau de confiabilidade de $95 \%$.

Recebido em: 31/10/2017

Primeira decisão editorial em: 25/02/2018

Aceito em: $22 / 03 / 2018$ 